\title{
An Amazing PFS with Icotinib in a Lung Adenocarcinomas Patient Harboring Rare Complex Gene Mutations: G719C/ S768I
}

\author{
Cai-hua Wang, Ting-ting Gu, Jie Zhang, Xiao-xiao Li and Jun-hong Jiang* \\ Department of Respiratory Medicine, the First Affiliated Hospital of Soochow University, China
}

Submission: November 16, 2018; Published: December 10, 2018

*Corresponding author: Jun-hong Jiang, Department of Respiratory Medicine of the First Affiliated Hospital of Soochow University, NO. 188 Shizi Street, Suzhou, Jiangsu 215006, China

\begin{abstract}
Background and purpose: Nowadays, epidermal growth factor receptor tyrosine kinase inhibitor (EGFR-TKI) targeted therapy has developed to be the standard therapy for patients with advanced lung adenocarcinomas harboring common EGFR mutations. But the efficacy for the so-called rare and especially for the very rare complex EGFR mutations is not clear.

Methods: We describe a case of a 61-year-old male with advanced lung adenocarcinomas harboring rare complex EGFR mutations (G719C and S768I), and observe the clinical efficacy of icotinib, We discuss our case with other literatures.

Results: he has a good clinical response to icotinib. His progression-free survival (PFS) has reached to 36 months.

Conclusion: It may suggest that lung adenocarcinomas patients harboring rare complex gene mutations (G719C/ S768I) have relatively good efficacy and safety to icotinib.
\end{abstract}

Keywords: PFS; icotinib; rare; complex gene mutation; G719C; S768I

Abbreviations: EGFR-TKI: Epidermal Growth Factor Receptor Tyrosine Kinase Inhibitor; PFS: Progression-Free Survival; NSCLC: Non-Small Cell Lung Cancer; CT: Computed Tomography; ALT: Alanine Aminotransferase; AST: Aspartate Aminotransferase; Scr: Serum Creatinine

\section{Introduction}

Lung cancer is the leading cause of cancer related mortality worldwide and non-small cell lung cancer (NSCLC) represents $80 \%$ of all lung cancers. EGFR mutations are found approximately in $10 \%$ to $20 \%$ of the Caucasian population and from $30 \%$ to $60 \%$ of the Asian population with NSCLC [1]. In recent years, EGFR-TKIs have improved to be the standard therapy for NSCLC with common EGFR mutations. However, the efficacy for rare complex EGFR mutations is not clear [2]. We herein report a case of a patient with adenocarcinoma of the lung exhibiting two rare mutations, G719C in exon 18 and S768I in exon 20. He was treated with icotinib, and his PFS has reached to an amazing number (36 months).

\section{Case Report}

A 61-year-old man with a 40-pack-year smoking history was admitted to our hospital in August 2015 because of an incidentally found mass in the lung. He underwent the right nephrectomy because of his right renal cyst in 2000. Physical examination revealed nothing of significance in the chest, abdominal regions, nor in the extremities. A computed tomography (CT) scan of the chest (Figure 1a) on 20, August 2015 revealed a 22-mm mass in the left lower lobe with multiple lung nodules in both lung fields without mediastinal lymph nodes enlargement. Fiberoptic bronchoscopy was performed in our hospital. He was diagnosed advanced lung adenocarcinomas. He had two cycles of chemotherapy (pemetrexed $500 \mathrm{mg} / \mathrm{m} 2$, day 1 , oxaliplatin $130 \mathrm{mg} / \mathrm{m} 2$, day 1$)$. The levels of alanine aminotransferase (ALT, 174.5U/L) and aspartate aminotransferase (AST, 106.4U/L) in the serum were significantly increased within one month after the first cycle of chemotherapy. Fortunately, in his specimen of brush biopsy, rare complex EGFR mutations (G719C in exon 18 with abundance $11.65 \%$ and S768I in exon 20 with abundance $18.46 \%$ ) were detected by the approach of next-generation sequencing. Then he received EGFR-tyrosine kinase inhibitor, gefitinib, as the second line treatment in a standard dose of $250 \mathrm{mg}$ per day from October 2015. But he underwent severe diarrhea and serious hepatic damage, his levels of ALT, AST and serum creatinine (Scr) rose up to the highest peak (ALT 488U/L, AST 358U/L, Scr 157umol/L) after three weeks. Then his drug usage was stopped for about half a month and dose of $250 \mathrm{mg}$ per day was reduced to $250 \mathrm{mg}$ every other day. Diarrhea and hepatic damage relieved half a month later. His chest CT (Figure 1b) on 28 November 2015, showed little smaller size in pulmonary lesion and multiple pulmonary nodules. 
Then gefitinib was changed to icotinib in a standard dose of 150 mg three times a day from December 2015 and no diarrhea and other complications occurred from then on. His levels of ALT and AST went back to normal and a follow-up chest CT (Figure 1c) on February 12, 2016, showed a decrease in tumor size as well as the multiple pulmonary nodules. His chest CT (Figure 1d) on July 02, 2018, showed smaller size of the cancer and several nodules disappeared without diarrhea or hepatic damage. Now the patient is in good condition with follow-up.

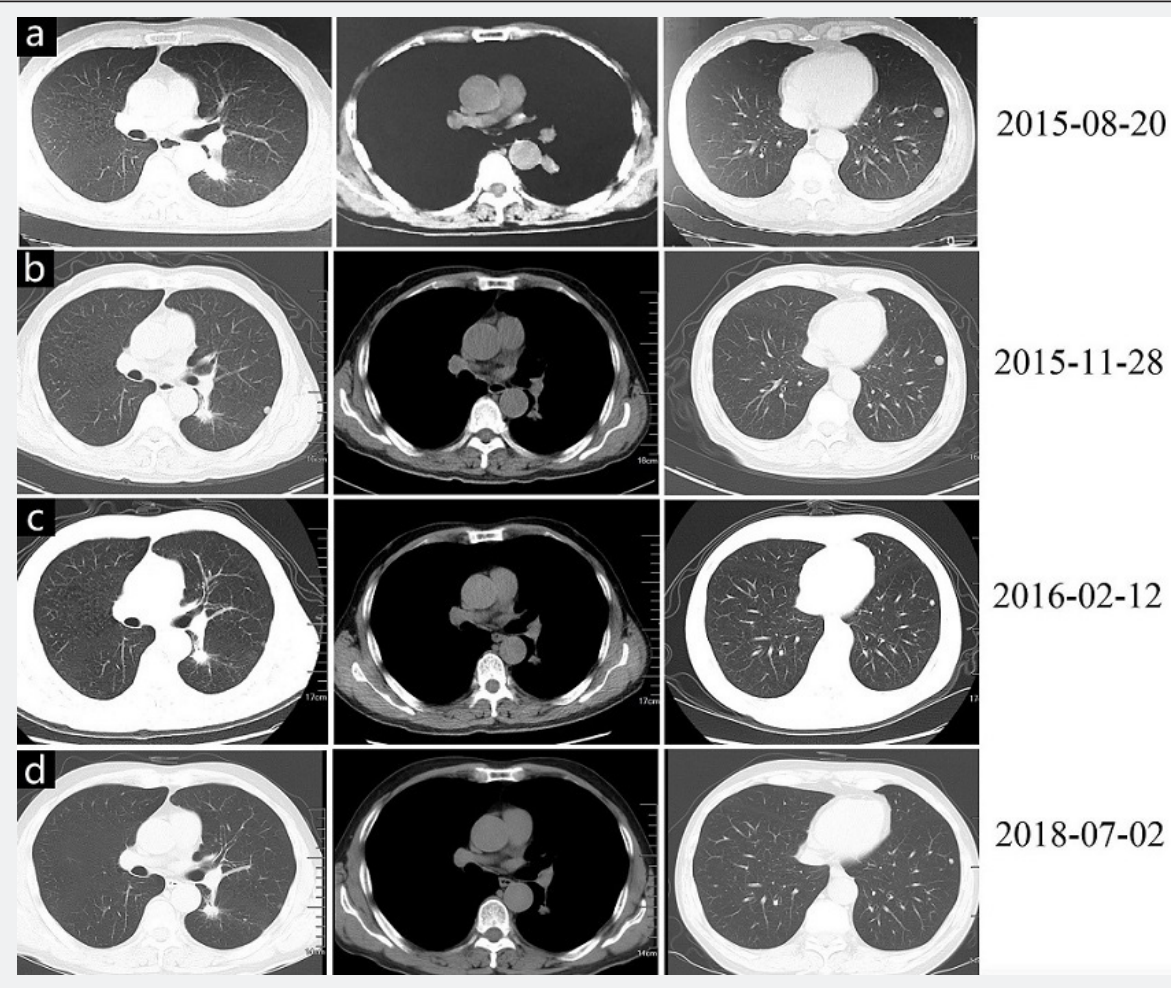

Figure 1: The manifestation of CT at different period.

(a) A 22-mm mass with multiple lung nodules.

(b) Smaller size in pulmonary lesion and nodules after two cycles of chemotherapy.

(c) A decrease in tumor size.

(d) A decrease in tumor size and several nodules disappeared.

\section{Discussion}

Exon 19 deletions and L858R point mutations in exon 21, are classical mutations, constituting $80-90 \%$ of EGFR mutations [3]. They are confirmed as sensitive mutations to EGFR-TKIs. With the clinical application of more sensitive and precise tumor genotyping systems, rare EGFR mutations, such as various point mutations, insertions, and double mutants, are also frequently encountered in routine clinical practice. S768I, a mutation in exon 20 , is one of those rare mutations and occurs approximately $1-2 \%$ in EGFR mutant of lung cancers [4]. G719C is also a very rare mutation in exon 18 of EGFR gene and is not often described in literatures. Compound EGFR mutations, defined as double or multiple independent mutations of the EGFR tyrosine kinase domain, comprise $14 \%$ of all mutations identified during routine sequencing of exons 18-21 of EGFR [5]. But the rare compound mutations with G719C and S768I are absolutely rare.

EGFR-TKIs have effective in the treatment of non-small cell lung cancer with common EGFR mutations. Nowadays, Gefitinib, erlotinib, afatinib and icotinib have been used in clinical practice. But the relationship between rare EGFR mutations and sensitivity to EGFR-TKI in NSCLC remains controversial. A retrospective analysis by Baek et al. [6] reported that patients with rare or complex mutations had inferior response and survival when treated with EGFR-TKIs compared with patients harboring common EGFR mutations. Chiu et al [7] indicated that the type of EGFR mutation was an independent predictor of EGFR-TKI treatment response. They proved patients with uncommon mutations had significant shorter PFS (median, 7.7 vs 11.4 months; $\mathrm{p}<0.001$ ) and overall survival (median, 17.2 vs 27.8 months; $p<0.001$ ) than that of patients with common mutations.

By contrast, one prior clinical case of an EGFR S768I mutant of lung adenocarcinoma reported apparent sensitivity to gefitinib with a PFS more than 15 months [8]. Hellmann et al. [9] reported a case which provided conclusive evidence that EGFR S768I mutant of lung adenocarcinomas was sensitive to erlotinib. Pasello et al. [10] proved that afatinib seemed to be effective in rare and complex mutations. Based on these findings, we hypothesized that cases with different type of mutations had different response to EGFR-TKIs.

In our case, the patient harboring the rare mutations (G719C/ S768I) received gefitinib as the targed therapy, but severe diarrhea and hepatic damage occurred. Then he started to take icotinib and achieved stable disease and his PFS was 36 months. From our case and literatures, it confirms that, the described complex 
EGFR mutations (G719C/ S768I) have relatively good sensitivity to icotinib. It is expected that such rare complex mutations may be more frequently detected with wider adoption of NGS-based tests. More dedicated efforts are needed to clarify their biologic effects on disease course and drug responsiveness.

\section{Financial Support and Sponsorship}

This work was supported by the Jiangsu Social Development Project (BE2016672).

\section{References}

1. Wu JY, Yu CJ, Chang YC, Yang CH, Shih JY, et al. (2011) Effectiveness of tyrosine kinase inhibitors on uncommon epidermal growth factor receptor mutations of unknown clinical significance in non-small cell lung cancer. Clin Cancer Res 17(11): 3812-3821.

2. Improta G, Pettinato A, Gieri S, Scandurra G, Skovrider-Ruminski W, et al. (2016) Epidermal growth factor receptor exon 20 p. S768I mutation in non-small cell lung carcinoma: A case report combined with a review of the literature and investigation of clinical significance. Oncol Lett 11(1): 393-398.

3. Keam B, Kim DW, Park JH, Lee JO, Kim TM, et al. (2014) Rare and complex mutations of epidermal growth factor receptor, and efficacy of tyrosine kinase inhibitor in patients with non-small cell lung cancer. Int J Clin Oncol 19(4): 594-600.

4. Arcila ME, Nafa K, Chaft JE, Rekhtman N, Lau C, et al. (2013) EGFR exon 20 insertion mutations in lung adenocarcinomas: prevalence, molecular heterogeneity, and clinicopathologic characteristics. Mol Cancer Ther 12(2): 220-229.

5. Kobayashi S, Canepa HM, Bailey AS, Nakayama S, Yamaguchi N, et al. (2013) Compound EGFR mutations and response to EGFR tyrosine kinase inhibitors. J Thorac Oncol 8(1): 45-51.

6. Baek JH, Sun JM, Min YJ, Cho EK, Cho BC, et al. (2015) Efficacy of EGFR tyrosine kinase inhibitors in patients with EGFR-mutated nonsmallcell lung cancer except both exon 19 deletion and exon 21 L858R: a retrospective analysis in Korea. Lung Cancer 87(2): 148-154.

7. Chiu CH, Yang CT, Shih JY, Huang MS, Su WC et al. (2015) Epidermal growth factor receptor tyrosine kinase inhibitor treatment response in advanced lung adenocarcinomas with G719X/L861Q/S768I mutations. J Thorac Oncol 10: 793-799.

8. Masago K, Fujita S, Irisa K, Kim YH, Ichikawa M, et al. (2010) Good clinical response to gefitinib in a non-small cell lung cancer patient harboring a rare somatic epidermal growth factor gene point mutation; codon 768 AGC > ATC in exon 20 (S768I). Jpn J Clin Oncol 40(11): 11051109.

9. Hellmann MD, Reva B, Yu H, Rusch VW, Rizvi NA, et al. (2014) Clinical and in vivo evidence that EGFR S768I mutant lung adenocarcinomas are sensitive to erlotinib. J Thorac Oncol 9(10): e73-e74.

10. Pasello G, Polo V, Frega S, Lorenzi M, Indraccolo S, et al. (2016) 166P: Non-small cell lung cancer (NSCLC) patients with rare or complex epidermal growth factor receptor (EGFR) mutations: A single institution series. J Thorac Oncol 11(4 Suppl): S130.

\section{Your next submission with Juniper Publishers will reach you the below assets}

- Quality Editorial service

- Swift Peer Review

- Reprints availability

- E-prints Service

- Manuscript Podcast for convenient understanding

- Global attainment for your research

- Manuscript accessibility in different formats ( Pdf, E-pub, Full Text, Audio)

- Unceasing customer service

Track the below URL for one-step submission https://juniperpublishers.com/online-submission.php 